\title{
When Do Firms Issue New Equity? Evidence from the UK
}

\author{
Heba $\mathrm{Ali}^{1}$ \\ ${ }^{1}$ Faculty of Management Technology, German University in Cairo, Cairo, Egypt \\ Correspondence: Heba Ali, Faculty of Management Technology, German University in Cairo, New Cairo City \\ 11835, Cairo, Egypt. Tel: 20-2-2758-9990-8. E-mail: Heba.abbas-ali@guc.edu.eg
}

Received: June 15, 2015

Accepted: September 6, $2015 \quad$ Online Published: September 25, 2015

doi:10.5539/ijef.v7n10p31

URL: http://dx.doi.org/10.5539/ijef.v7n10p31

\begin{abstract}
Earlier evidence has shown that there are substantial time-varying fluctuations in the issuance activity of IPOs and SEOs. Utilizing a comprehensive dataset of 3054 IPOs and 2853 rights issues launched on the London Stock Exchange (LSE) during the time periods (1987-2007) and (1975-2007) respectively, this study aims to conduct a comprehensive analysis of the main alternative determinants of timing of IPOs and rights issues in a unified framework. Three main theories are tested: (i) favorable business and economic conditions; (ii) stock market conditions: bull market timing versus behavioral timing, and (iii) decreasing adverse selection costs and information spill-over. This study explicitly deals with the methodological and econometric challenges associated with modeling the IPOs and rights issues as time-series non-negative count variables via using auto-regressive Poisson model. The findings are significantly consistent with the adverse selection story; firms tend to make more equity offerings during periods of reduced asymmetric information and market uncertainty, robust to the data frequency and variables tested. These findings stand in line with Gerbich (1996) for UK IPOs and Lowry and Schwert (2002) for US IPOs. For rights issues, the findings exhibit that UK seasoned firms tend to time their offerings mostly during periods of bull stock prices, which is consistent with Michailides (2000) for UK rights issues.
\end{abstract}

Keywords: Initial public offerings (IPOs), rights issues, favorable economic conditions, bull market, behavioral timing, information spillover

\section{Introduction}

Earlier evidence has shown that there are substantial time-varying fluctuations in the issuance activity of IPOs and SEOs on various international markets (e.g. Bayless \& Chaplinsky, 1996; Rajan \& Servaes, 1997; Helwege \& Liang, 2004; Benninga, Helmantel \& Sarig, 2005; Pástor \& Veronesi, 2003; Alti, 2006; Yung, Colak \& Wang, 2008; Yongyuan, 2008). Conceptually, these fluctuations in the IPOs and SEOs issuance activity are related to other terms so-called 'timing, and 'hot issues' markets, that is, the time-varying fluctuations in the number of equity-issuing firms, which in turn causes 'hot issues' markets and 'cold issues' market, are attributed to the tendency of firms to time their equity offerings at the same time. The existence of these substantial time-varying fluctuations in the issuance activity adds another puzzling question to the IPO and SEO literatures (e.g. Ibbotson, Sindelar \& Ritter, 1994; Rajan \& Servaes, 1997; Lower \& Schwert, 2002). To explain these swings, numerous theories have been put forward and various models have been suggested, yet it is still under-investigated question (e.g. Rees, 1997; Hoffmann-Burchardi, 2001; Lowry \& Schwert, 2002; Lowry, 2003; Pástor \& Veronesi, 2005; Alti, 2005; Yung et al., 2006).

Generally, the proposed interpretations can be summarized into three main theories: (i) favorable economic and business conditions; (ii) stock market conditions: bull market timing versus behavioral timing, and (iii) decreasing adverse selection costs and information spill-over. According to the first hypothesis, timing of equity issues (IPOs and SEOs) is directly related to the growing economy-wide demand for capital and lower uncertainty associated with prosperous macro-economic phases (e.g. Ljungqvist, 1995; Rees, 1997; Qian, 2005). On the other hand, other studies posit that firms are expected to issue more equity when the level of information asymmetry between the issuers and investor and consequently the adverse selection costs are low (e.g. Myers \& Majluf, 1984; Choe, Masulis \& Nanda, 1993). Various studies have also adopted the market conditions hypothesis to interpret timing of IPOs and SEOs. Here, market conditions hypothesis can imply that managers take advantage of bull markets and attractive stock prices when timing their offerings (i.e. bull market timing) or alternatively managers exploit periods of prevailing mis-valuations and/or the investor over-optimism (i.e. 
behavioral timing). Empirically, the argument of behavioral timing and how it can impact timing of IPO and SEO has recently received great attention and support (Aggarwal \& Rivoli, 1990; Ritter \& Welch, 2002; Cook, Jarrel \& Kieschnick, 2003; Ljungqvist, 2006).

In this research, I investigate the determinants of the substantial time-varying fluctuations in the issuance activity of UK IPOs and rights issues, represented by three main hypotheses: (i) favourable economic and business conditions; (ii) stock market conditions: bull market timing versus behavioural timing, and (iii) decreasing adverse selection costs and information spill-over. Indeed, some of these hypotheses have been tested before in several studies in the UK context, yet these studies have examined only different subsets of these theories, with financial modelling subject to several econometric critiques. In specific, the UK IPOs activity in the context of timing has been examined by Loughran, Ritter, and Rydqvist (1994), Gerbich (1996), Rees (1997), Michailides (2000) and Gregory, Guermat and Al-Shawawreh (2010), whilst the timing of UK rights issues has been only examined by Michailides (2000) (Note 1). On the other hand, modeling the IPOs and rights issues, as a time-series count variable, empirically poses a number of econometric difficulties, so any modeling attempts should account for these econometric considerations (Ljungqvist, 1995), yet none of the UK-based studies are found to provide an adequate modeling that simultaneously incorporates both the time-series and statistical properties of the IPOs and rights issues variables.

Loughran et al. (1994), in their study on a number of the European markets, considered only two explanatory variables: stock market level and real GNP growth, whilst Gerbich (1996) examined the impact of economic and business conditions, proxied by cyclical economic indicators, and the stock market level. Rees (1997) only explored the impact of the stock market level, cyclical economic indicator, and T-bill rate. Michailides (2000) examined a wider range of variables: interest rate, the stock market level, market volatility, economic cycle dummy, change in consumer confidence index, change in T-bill rate and change in long-run governmental bonds. Gregory et al. (2010) examined the prediction power of lagged dependent variable, market return and Fama-French factors (the return on SMB and the return on HML). With respect to rights issues, there are no studies-other than Michailides (2000)-that has examined the timing of rights issues for the UK. In Michailides' (2000) study, the tested explanatory variables are: interest rate, the stock market level, market volatility, economic cycle dummy, change in consumer confidence index, change in T-bill rate and change in long-run governmental bonds.

This study adds to the literature in several ways. This study directly examines and evaluates these theories in a comprehensive and unified way in the UK context, in addition to expanding the examined range of explanatory variables utilized as proxies in hypotheses testing. Also, in this study I distinguish between bull market hypotheses and behavioral timing hypotheses in a way that takes in consideration the alternative explanations of stock market conditions hypothesis. As an original contribution, this study directly examines the behavioral timing hypothesis in the UK context through testing the impact of an investor sentiment proxy, presented by the discount on closed-end funds (DCEF), constructed following Lee, Shleifer, and Thaler (1991), on the issuance activity of UK IPOs and rights issues. Also, this study sheds light to the question whether and how the gilt to equity ratio (GEYR) is linked to the equity issuance activity. This has not been tested before in the literature. This study, via testing this link, extends the conventional stock market proxies tested in the literature.

Methodologically, I utilize auto-regressive Poisson Model that most appropriately incorporates the non-negative count nature of IPOs and rights issues volume and simultaneously captures the time-series properties as well (Note 2). As a further measure of robustness, Auto-Regressive Poisson are estimated with monthly as well as quarterly data to check the persistence of the results across different data frequencies. In addition, including two different forms of equity issues (IPOs and rights issues) in the study's analysis allows for investigating if IPOs and rights issues are timed in a different manner, which provides an opportunity to compare the determinants of timing of issuance and check its robustness. Also, examining the UK rights issues lunched from 1975 to 2007 provides the opportunity to reassess Michailides (2000) results, especially because his study period finishes in 1996, when the choice of floatation method was fully derestricted after the LSE relaxed the rules on the maximum size of a placing issue, and the UK right issues market has dramatically changed thereafter.

The paper now proceeds as follows. Section 2 reviews the literature review and develops the hypotheses set out to test. Section 3 describes the methodology, time-series tests and data collected. Section 4 presents the empirical results and discusses the robustness checks. Finally, Section 5 includes summary and conclusions.

\section{Literature Review and Hypotheses Development}

The firm decides to raise new equity if the benefits of this action overweigh its costs. The immediate question here is whether the firm times this offering. If so, the arrival rate of offerings (i.e. the number of firms coming to 
the market at the same time) is expected to exhibit substantial variations over time, which causes the so-called "cycles" or "waves" in issuance activity. The time-series variations in the IPO and SEO activity that has been subjected to extensive investigation are mainly attributed to three key theories: (i) favorable business and economic conditions; (ii) stock market conditions: bull market timing versus behavioral timing, and (iii) decreasing adverse selection costs and information spill-over.

According to the first theory, firms tend to raise new capital during expansionary economic cycles during which profitable investment opportunities and positive net present value projects are more likely to come up and so economy-wide demand for capital becomes higher (e.g. Choe et al., 1993; Gerbich, 1996; Michailides, 2000; Lowry, 2003). Furthermore, the managers' uncertainty about their future profitability tends to decrease and the economic agents' confidence and optimism presumably improve during these prosperous macro-economic phases. This link has been extensively examined and supported by the literature. For example, Mikkelson, Partch and Shah (1997) and Brau and Fawcett (2006) in their surveys for US firms find that the decision to go public is influenced by the need for new capital to support growth. Numerous studies, including Loughran et al. (1994), Rees (1997), Ljungqvist (1995), Rajan and Servaes (2002), Lowry (2003) and Pastor and Veronesi (2005) find a significant impact of economic and business indicators, such as GNP, aggregate profitability or business cycles indicators, on the IPO activity on various international markets. Similarly, the positive relationship between favorable economic and business conditions and the SEOs activity is empirically supported by Harjoto and Garen (2003), Qian (2005), Wagner (2007) and Rau and Stouraitis (2011).

The market conditions hypothesis is tested in the literature in two ways: bull market timing versus behavioral timing. Bull market timing indicates an overall favorable market situation in which managers take advantage of bull markets attempting to capture attractive stock prices without contradiction with the efficient market hypothesis $(\mathrm{EMH})$. On the other hand, behavioral timing hypothesis posits that firms time their offerings to coincide with periods of stock mis-valuations and/or investor sentiment in the markets, which implies that the investor is not rational and the market is not efficient. In support of the bull market hypothesis, the literature shows various empirical evidence on the existence of a positive association between IPOs issuance and stock index levels (e.g. Rees, 1997; Michailides, 2000; Burgstaller, 2009) and stock index returns (e.g. Rydqvist \& Hogholm, 1995; Breinlinger \& Glogova, 2002; Pastor \& Veronesi, 2005). For the SEOs, there are only few studies that directly examine the link between the SEOs issuance activity and market conditions proxies, such as Wagner (2007) and Howe and Zhang (2010).

Alternatively, the behavioral timing-based interpretations of IPO and SEO timing have been investigated and adopted by wide range of studies. Conceptually, this hypothesis implies that firms can observe stock overvaluations and investor sentiment in the first place. Methodologically, this is unobservable, that is, we cannot certainly say firms ex ante knew about the degree of mispricing and investor sentiment and timed their offerings accordingly, and neither can we directly observe these forms of market irrationality ex post. So, alternative measures serving as proxies for overvaluations and investor sentiment have to be used, such as the discounts of closed-end funds (DCEF) and earnings growth forecasts (Note 3). Numerous studies, such as Lee et. al. (1991), Rajan and Servaes (1997), Pagano, Panetta and Zingales, (1998), Ljungqvist, Nanda and Singh (2002), Lowry (2003), Ritter and Welch (2002), Helwege and Liang (2004), Chiu (2005) and Chen and Cheng (2008) exhibit a significant direct association between several investor sentiment proxies and the timing of IPOs and SEOs.

According to the third main hypothesis, firms tend to raise new equity to take advantage of the prevailing decrease in adverse selection costs and resulting information spill-over, which realizes through the information, generated about a set of pioneers and reduces uncertainty for the follower issuers (Lowry \& Schwert, 2002). Empirically, as the adverse selection costs cannot be directly observed, various proxies for adverse selection costs are therefore proposed, such as the degree of under-pricing, firm age and size and dispersion in earning forecasts. For IPOs, the findings have exhibited mixed evidence (e.g. Gerbich, 1996; Michailides, 2000, Lowry \& Schwert, 2002; Yongyuan, 2008). For SEOs, there are only few early studies that shed light on the timing of the SEOs, including Korajczyk, Lucas and McDonald (1988), Dierkens (1991) Choe et al. (1993) and Bayless and Chaplinsky (1996), finding that the timing decision is mainly driven by the degree of information asymmetry.

In the UK context, there is limited number of studies-as displayed before-that has directly examined and evaluated the above-mentioned theories in a comprehensive way. In addition, the financial modeling of IPOs and rights issues, as a time-series and non-negative count variable, encounters a number of econometric and methodological difficulties. However, none of the UK-based studies are found to provide an adequate modeling that simultaneously incorporates both the time-series and statistical properties of the IPOs and rights issues 
variables. In this study, I undertake a comprehensive analysis of all the alternative hypotheses in a unified framework, employing auto-regressive Poisson Model across different data frequencies. Building on the above-mentioned discussions, I formulate my hypotheses as follows:

H1: Economic and business conditions hypothesis: the volume of IPOs increases during periods of favorable economic and business conditions.

H2: Economic and business conditions hypothesis: the volume of rights issues increases during periods of favorable economic and business conditions.

H3: Bull market timing hypothesis: the volume of IPOs increases during periods of favorable stock market conditions.

H4: Bull market timing hypothesis: the volume of rights issues increases during periods of favorable stock market conditions.

H5: Behavioral timing hypothesis: the volume of IPOs increases during periods of high investor sentiment.

H6: Behavioral timing hypothesis: the volume of rights issues increases during periods of high investor sentiment.

H7: Adverse selection costs and information spill-over hypothesis: the volume of IPOs increases during periods of lower adverse selection costs and higher information spill-over.

H8: Adverse selection costs and information spill-over hypothesis: the volume of rights issues increases during periods of lower adverse selection costs and higher information spill-over.

\section{Data and Methodology}

\subsection{Time-Series and Statistical Properties of IPOs and Rights Issues}

Any attempts to model the IPOs and rights issues series should account for a number of important econometric and methodological considerations imposed by the characteristics of these series, such as non-negative count nature, non-normality and autocorrelation. Ignoring these statistical and time-series features produces non-normal, heteroscedastic and serially-correlated residuals, and so results in inconsistent estimates and biased standard errors (Ljungqvist, 1995; Long, 1997). Consistent with prior evidence, monthly IPO volume is found to be highly persistent over time; the first-order autocorrelation of monthly IPO volume between 1987 and 2007 is 0.583 , with Portmanteau test of $888.6(\mathrm{p}<.0001)$ that rejects the hypothesis of no serial correlation. Also, the distribution of the number of IPOs is far from normality with Jarque-Bera test statistic of 155.7. Similarly, the first-order autocorrelation of monthly volume of rights issues between 1975 and 2007 is 0.655 , with Portmanteau test of 2326.2 ( $\mathrm{p}<.0001)$ that rejects the hypothesis of no serial correlation. Also, the distribution of IPOs and rights issues is far from normality with Jarque-Bera test statistic of 155.7 and 113.4 respectively.

Researchers, in attempting to consider these properties, have changed the characteristics of the data to meet the assumptions of traditional statistical methods and/or utilized other statistical methods that are claimed to be more appropriate for the count nature of the data (e.g. Tobit or Poisson regressions). However, to simultaneously account for both these time-series and statistical properties of the IPOs volume, these ways need to be extendedly modified. To do so, I use auto-regressive Poisson Model that captures both the non-negative count nature and the time-series properties of IPOs and SEOs volume. To check the findings robustness, the model will be estimated utilizing different data frequencies (monthly vs. quarterly). A full description of the model is presented in appendix A. Overall, there is an observable seasonality in the time-series of IPO and rights issues (Note 4). To adjust for these seasonal characteristics, a set of seasonal dummies will be included for the seasonal months and quarters of the year. To control for the time-series features of the UK IPOs and rights issues, I control for the long-term trend in the UK IPOs activity by including a linear trend in the IPOs regressions (Note 5). For rights issues, I will include a dummy variable equal to one after the year 1996 and zero otherwise, to capture the impact of the UK regulatory changes in 1996.

\subsection{Time-Series Tests and Variable Definition}

To investigate the influence of economic conditions on the issuance activity of IPOs and rights issues, a business cycle dummy that equals to one if the current period is an expansion and zero otherwise is added. So, a composite coincident index is selected to measure the aggregate economic activity (i.e. designating the turning points in the business cycle). I construct a composite coincident index of the UK economy, following the methodology applied by Conference Board (CB), comprising of industrial production, retail sales, employment, and real household disposable income during the period from 1975 to 2007 (Note 6). During the study period (1975-2007), the UK economy has experienced three major recessions between 1973 Q3 and 1975 Q3, between 
1979 Q3 and 1981 Q1, and between 1990 Q3 and 1992 Q2. Figure 1 plots the percentage change in composite coincident index during the period (1975-2007) and compares it to the real GDP growth rate, which notably appear to move closely together. Another proxy for economic conditions (i.e. the consumer attitude about the current and prospective macroeconomic conditions) is represented by the level and change in consumer confidence index (CCI). Empirically, UK-based studies exhibit supportive evidence on the predictive power of consumer confidence index (CCI) in measuring the UK economic activity (e.g. Taylor \& McNabb, 2007).

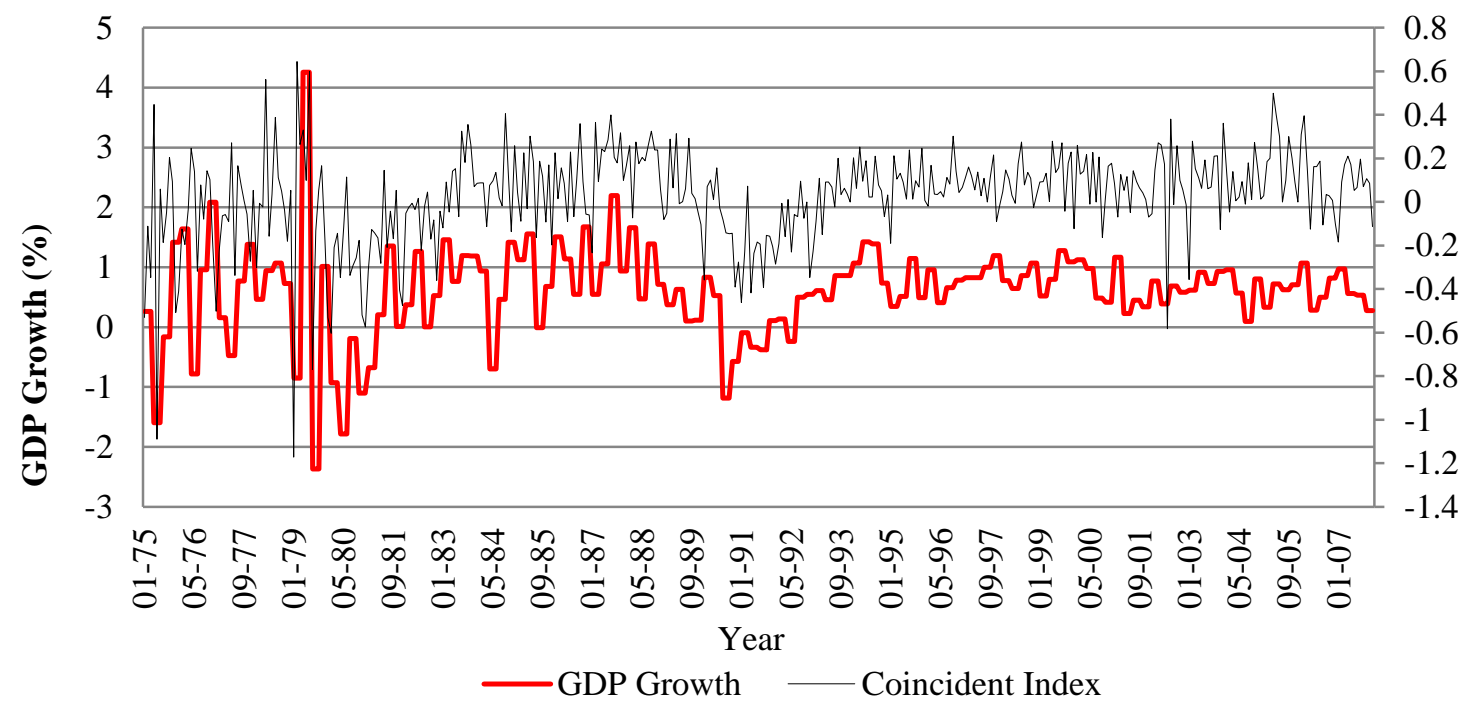

Figure 1. Real GDP growth and composite coincident index over (1975-2007)

With regard to the bull market proxies, I use 30,60 and 180-day cumulative returns of the FTSE All Share (i.e. market run-up) as a measure of the stock market level. The stock market conditions can be also captured by the ratio of FTSE level to its 3-year moving average, which measure how well the market is performing in regard to its history (i.e. market level). Also, firms might prefer raising new equity when the price of alternative sources of capital is increasing, which suggests a positive relation between the cost of borrowing and the equity issuance activity. The cost of fixed interest capital (borrowing) is represented by the percentage change rate of the 3 -month treasury rate. In a similar context, firms may prefer raising new equity during periods of high market valuations relative to other capital markets (i.e. bond market). Empirically, fund managers and financial analysts have widely used the gilt to equity yield ratio (GEYR)-estimated as a ratio of the income yield on long-term government bonds to the income yield on equity-to measure the relative value of equity over bonds and to assess the substitution effects between the two markets (e.g. Harris \& Rene, 2000; Migiakis \& Bekiris, 2009). Built on that, a positive relation between the GEYR and issuance activity can be proposed (i.e. issuers tend to time their offerings to coincide with periods of high equity valuations as indicated by high GEYRs). As a proxy for investor sentiment and behavioral timing, I construct the discount on closed-end funds (DCEF) following Lee et al. (1991). The discount index for a given month is measured as the equally-weighted average of the DCEFs in the UK at the end of the month. Based on Lee et al. (1991), the fluctuations in discounts of closed-end funds (DCEFs) are claimed to be driven by changes in investor sentiment that is basically driven by the irrationality of investors; discounts are high (low) when investors are pessimistic (optimistic) about future returns, and so investors pay relatively less (more) for closed-end fund. Thus, according to the behavioral timing hypothesis, the issuance activity of IPOs and rights issues is predicted to negatively move with this discount (Note 7).

To test the information asymmetry hypotheses, I use two proxies for the degree of information asymmetry as suggested by the literature: market volatility and the market reaction to the equity issue (i.e. measured by the level of under-pricing for IPOs and the abnormal announcement-period returns for rights issues). High degrees of under-pricing can indicate a satisfactory demand for IPOs, disclose positive information for subsequent similar IPOs, and so motivate more firms to go to the market (Lowry \& Schwert, 2002). Accordingly, there is a positive impact of the magnitude of under-pricing on the future IPOs arrivals can be realized through information spill-over effect. As a measure of under-pricing, I use the average first day returns of all the IPOs in the previous 
3 months. In the SEOs context, the announcement of SEOs has been generally shown to convey negative information to the market in form of negative abnormal stock returns around the announcement of the offerings. Firms are likely to increase their offerings following periods of decreased information asymmetry and adverse selection costs. As a measure of the adverse selection costs, I use a measure of the abnormal announcement-period returns for all the rights issues made in the last quarter. The returns are measured based on cumulative average abnormal returns (CAARs) using market model methodology. Higher announcement-period returns (i.e. becomes less negative, indicating lower adverse selection costs) are expected to encourage more firms to go to the market. The second proxy for the degree of stock market uncertainty is the market volatility which is expected to exert a negative influence on the issuance volume of IPOs and rights issues. I use measures of 90-day market volatility as an explanatory variable.

\subsection{Data}

The IPOs sample consists of the new firms listed (placings and offers) on the London Stock Exchange (Main Market, the Alternative Investment Market (AIM) and the Unlisted Securities Market (USM)) over the period (1987-2007). Data is hand-collected and cross-matched mainly from 'Market Quality Quarterly Issues' for the sample period (1987-1996) and London Stock Exchange's website for the sample period (1997-2007). The final sample consists of 3054 IPOs (excluding privatizations). This study uses large data set of UK IPOs, compared to prior studies on UK IPOs, such as Loughran et al. (1994), Gerbich (1996), Michailides (2000) and Gregory et al. (2010). Loughran et al.'s (1994) sample includes 1861 IPOs from 1960 to 1991. Gerbich's (1996) sample consists of 1261 IPOs between 1981 and 1995. Michailides' (2000) sample consists of 1262 IPOs over the period (1981-1996) while Gregory et al. (2010) examine a set of 2499 IPOs between 1975 and 2004. Table 1 summarizes the activity of UK IPOs over the time-period (1987-2007). Over the study period, a total of approximately $£ 129$ billion (measured in 2007 prices) has been raised by 3054 IPOs, with average of $£ 6.14$ million is being raised yearly (measured in 2007 prices). On average, 146 new firms go to the market per year, with a record of 416 new firms being listed on the London stock Exchange (LSE) in the year 2005. This appears to be driven by a number of factors, such as significant economic recovery in 2004/2005 and the continued success of Alternative Investments Market (AIM), London's exchange-regulated smaller companies' market, in attracting many small companies between 2004 and 2006. In contrast, early nineties were the years with the lowest volume with only 33 firms going public, which appears consistent with the UK economic recession in the period (1990-1992).

Table 1. The annual distribution of the IPOs activity in the UK over the time-period (1987-2007)

\begin{tabular}{lcccc}
\hline & \multicolumn{2}{c}{ Number of IPOs } & \multicolumn{2}{c}{ Amount of Money Raised (in 2007 Prices) } \\
\cline { 2 - 5 } Year & Total & Monthly Average & Total (£b) & Monthly Average (£m) \\
\hline $\mathbf{1 9 8 7}$ & 113 & 9.4 & 1.28 & 11.4 \\
$\mathbf{1 9 8 8}$ & 130 & 10.8 & 2.10 & 46.2 \\
$\mathbf{1 9 8 9}$ & 87 & 7.3 & 4.04 & 49.2 \\
$\mathbf{1 9 9 0}$ & 33 & 2.8 & 1.62 & 108.5 \\
$\mathbf{1 9 9 1}$ & 34 & 2.8 & 3.69 & 54.2 \\
$\mathbf{1 9 9 2}$ & 36 & 3.0 & 1.95 & 54.8 \\
$\mathbf{1 9 9 3}$ & 107 & 8.9 & 5.86 & 74.2 \\
$\mathbf{1 9 9 4}$ & 147 & 12.3 & 10.91 & 37.9 \\
$\mathbf{1 9 9 5}$ & 79 & 6.6 & 3.00 & 32.1 \\
$\mathbf{1 9 9 6}$ & 162 & 13.5 & 5.20 & 18.8 \\
$\mathbf{1 9 9 7}$ & 116 & 9.7 & 2.16 & 52.6 \\
$\mathbf{1 9 9 8}$ & 88 & 7.3 & 4.62 & 51.5 \\
$\mathbf{1 9 9 9}$ & 105 & 8.8 & 5.40 & 39.7 \\
$\mathbf{2 0 0 0}$ & 281 & 23.4 & 11.16 & 49.3 \\
$\mathbf{2 0 0 1}$ & 153 & 12.8 & 7.54 & 62.7 \\
$\mathbf{2 0 0 2}$ & 91 & 7.6 & 5.70 & 47.8 \\
$\mathbf{2 0 0 3}$ & 78 & 6.5 & 3.72 & 23.5 \\
$\mathbf{2 0 0 4}$ & 280 & 23.3 & 6.59 & 30.8 \\
$\mathbf{2 0 0 5}$ & 386 & 32.2 & 11.87 & 52.4 \\
$\mathbf{2 0 0 6}$ & 323 & 26.9 & 16.92 & 60.6 \\
$\mathbf{2 0 0 7}$ & 225 & 18.8 & 13.62 & \\
\hline Total & $\mathbf{3 0 5 4}$ & & $\mathbf{1 2 8 . 9 9}$ & 60.9 \\
\hline
\end{tabular}

Note. In table 1, amount of money raised in IPOs is measured in 2007 prices using GDP deflator. 
The UK rights issues sample consists of the UK firms that have had rights issues from 1975 to 2007. The details of the offerings (e.g. money raised and announcement date) are hand-collected from various published issues of 'Extel Takeovers, Offers and New Issues' and then crossed with Rights Issues Diary files available on Thomson Reuters Datastream for the years (1975-1998) and London Stock Exchange's (LSE) website for the years (1998-2007). The final sample is reduced to 2853 issues, compared to a sample of 1569 rights issues during the period (1975-1996) used by Michailides (2000). As exhibited in Table 2, a total of 2853 UK rights issues have been launched by 1579 listed firms over the period (1975-2007), raising a total amount of £181.4 billion. Out of these 1579 firms, 856 firms make only one rights issue, 395 firms make twice, 186 firms make thrice, and 88 firms make rights issues four times. In addition, there are 33 firms that go to the market five times, 17 firms that go to the market six times, and 2 firms that go to the market seven and eight times. In terms of the number of rights issues, there are on average $86 \mathrm{UK}$ rights issues that are made every year. As shown, this number substantially varies across time with 1987 and 1993 being the busiest years (176 rights issues). Since 1986, the UK legal and institutional framework has changed as other forms of SEOs (open offers and placing) are permitted in the UK market, followed by a full deregulation of the choice of the SEO floatation method in 1996. This is obviously reflected in the substantially decreasing number of subsequent rights issues coming to the market after 1996, with only five rights issues made in 2007. The amount of capital raised (measured in 2007 prices) also substantially fluctuates over the study period, peaking at early nineties (i.e. 1991 and 1993).

Table 2. The annual distribution of the activity of UK rights issues over the time-period (1975-2007)

\begin{tabular}{|c|c|c|c|c|}
\hline & \multicolumn{2}{|c|}{ Number of Rights } & \multicolumn{2}{|c|}{ Amount of Money Raised (in 2007 Prices) } \\
\hline & & Monthly Average & Total (£b) & Monthly Average (£m) \\
\hline 1975 & 134 & 11.2 & 6.5 & 48.6 \\
\hline 1976 & 110 & 9.2 & 4.4 & 39.8 \\
\hline 1977 & 108 & 9 & 3.3 & 31 \\
\hline 1978 & 69 & 5.8 & 1.5 & 22.1 \\
\hline 1979 & 65 & 5.4 & 2.2 & 33.9 \\
\hline 1980 & 80 & 6.7 & 3.7 & 46.7 \\
\hline 1981 & 92 & 7.7 & 4.5 & 48.9 \\
\hline 1982 & 61 & 5.1 & 2 & 33.4 \\
\hline 1983 & 121 & 10.1 & 4.1 & 34.2 \\
\hline 1984 & 83 & 6.9 & 2.9 & 34.5 \\
\hline 1985 & 116 & 9.7 & 6.7 & 57.5 \\
\hline 1986 & 157 & 13.1 & 8.8 & 55.9 \\
\hline 1987 & 176 & 14.7 & 12.9 & 73.3 \\
\hline 1988 & 147 & 12.3 & 9.5 & 64.9 \\
\hline 1989 & 145 & 12.1 & 8.2 & 56.4 \\
\hline 1990 & 120 & 10 & 5.9 & 49.4 \\
\hline 1991 & 165 & 13.8 & 13.8 & 83.8 \\
\hline 1992 & 84 & 7 & 5.3 & 62.9 \\
\hline 1993 & 176 & 14.7 & 15.8 & 89.8 \\
\hline 1994 & 139 & 11.6 & 7.2 & 52 \\
\hline 1995 & 89 & 7.4 & 5.2 & 58.4 \\
\hline 1996 & 111 & 9.3 & 6.8 & 61.1 \\
\hline 1997 & 64 & 5.3 & 2.5 & 39.6 \\
\hline 1998 & 42 & 3.5 & 1.8 & 43 \\
\hline 1999 & 44 & 3.7 & 2.5 & 57 \\
\hline 2000 & 36 & 3 & 4.7 & 129.8 \\
\hline 2001 & 25 & 2.1 & 7.7 & 306.7 \\
\hline 2002 & 22 & 1.8 & 6.9 & 315.5 \\
\hline 2003 & 16 & 1.3 & 2.6 & 163.6 \\
\hline 2004 & 18 & 1.5 & 2 & 112.3 \\
\hline 2005 & 17 & 1.4 & 2.5 & 146.8 \\
\hline 2006 & 16 & 1.3 & 6.1 & 384.2 \\
\hline 2007 & 5 & 0.4 & 0.6 & 119.2 \\
\hline Total & 2853 & & 181.4 & \\
\hline
\end{tabular}

Note. In table 2, amount of money raised is measured in 2007 prices using GDP deflator. 
Data on explanatory variables are retrieved from various databases: data on daily stock prices, market indexes, economic variables (i.e. industrial production, retail sales, employment, real household disposable income and consumer confidence index) and long-term gilts are sourced from Datastream, data on 3-month treasury bills are collected from Bank of England, data on the UK closed-end fund discount are collected from Morningstar database, and data on equity dividend yield is sourced from the London Business School Share Price Database (LSPD). Summary statistics of the variables are presented in Tables 3 and 4 respectively. The monthly average (median) number of IPOs is 12.1 (9), ranging from a low of zero IPOs to a high of 62 IPOs, while the monthly average (median) number of rights issues is 7.2 (6), ranges from zero issues to 30 rights issues. At the quarterly level, the average (median) number of IPOs is 36.4 (30), compared to an average (median) number of rights issues of 21.6 (20), fluctuating from 3 to 113 for IPOs and from zero to 75 for rights issues. Explanatory variables have also exhibited an obvious degree of variation over the sample periods. For example, the cumulative 6-month market return varies from -42 percent to 92 percent over a 396-month time series (1975-2007). The stock market volatility shows substantial variation from a low of 42.9 percent to a high of 311.2 percent over the same period. On average, the IPOs under-pricing is 12.1 percent, substantially varies from -1.9 percent to 96.6 percent over a 252 -month time series (1987-2007). In contrast, the average abnormal announcement returns is -1.5 percent, ranging from -34.3 percent to 24.3 percent over a 396 -month time series (1975-2007). The correlation coefficients between the dependent and independent variables based are exhibited respectively in Appendix B, Tables B1 and B2 for the IPOs and in Tables B3 and B4 for rights issues.

Table 3. Descriptive statistics for IPOs regressions

\begin{tabular}{lcccccccccc}
\hline & \multicolumn{4}{c}{ Monthly Interval: 1987-2007 } & \multicolumn{5}{c}{ Quarterly Interval: 1987-2007 } \\
\cline { 2 - 10 } & Mean & Median & Std. Dev. & Max & Min & Mean & Median & Std. Dev. & Max & Min \\
\hline _Num_ IPOs & 12.10 & 9.00 & 10.70 & 62.00 & 0.00 & 36.40 & 30.00 & 26.50 & 113.00 & 3.00 \\
_BC & 0.91 & 1.00 & 0.29 & 1.00 & 0.00 & 0.91 & 1.00 & 0.30 & 1.00 & 0.00 \\
_CCI & 1.00 & 1.00 & 0.01 & 1.04 & 0.96 & 1.01 & 1.01 & 0.02 & 1.05 & 0.95 \\
_ $\Delta$ CCI (\%) & 0.01 & 0.04 & 0.48 & 1.27 & -1.48 & 0.01 & 0.04 & 0.36 & 0.80 & -1.43 \\
_ML & 1.12 & 1.13 & 0.16 & 1.62 & 0.65 & 1.12 & 1.14 & 0.16 & 1.63 & 0.65 \\
_MRun (\%) & 4.03 & 5.34 & 10.50 & 33.32 & -33.37 & 4.08 & 5.98 & 11.25 & 33.32 & -33.37 \\
_ $\Delta$ 3bills (\%) & 0.38 & 0.30 & 4.52 & 21.75 & -26.36 & -0.52 & -0.28 & 8.04 & 19.88 & -22.72 \\
_GEYR & 1.94 & 2.03 & 0.38 & 3.38 & 1.13 & 1.99 & 2.05 & 0.39 & 3.26 & 1.13 \\
_DCEF & 9.90 & 9.68 & 2.50 & 17.33 & 1.27 & 9.59 & 9.86 & 3.92 & 17.70 & 2.48 \\
_MV (\%) & 87.70 & 75.20 & 39.20 & 268.20 & 42.90 & 86.30 & 76.00 & 37.50 & 250.80 & 43.40 \\
_IPO UP (\%) & 12.07 & 9.47 & 12.31 & 96.64 & -1.88 & 12.08 & 9.16 & 12.50 & 84.58 & 0.00 \\
\hline
\end{tabular}

Note. _num_IPOs= number of IPOs; _BC= Business cycle dummy equals to one during periods of economic expansions and zero otherwise; _CCI= Consumer confidence index level; $\_\Delta \mathrm{CCI}(\%)=$ percentage change in consumer confidence index $(\mathrm{CCI})$; $\_\mathrm{ML}=\mathrm{Market}$ level indicator, measured as the ratio of FTSE All-Share index relative to its 12-month moving average; _MRun (\%)= cumulative 6-month FTSE returns; $\_$3bills $(\%)=$ the percentage change in 3-month T-bill; _GEYR= gilt to equity yield ratio;_DCEF= the level of the average discounts on closed-end funds; _MV $(\%)=$ the percentage 90-day market volatility, _IPO UP $(\%)=$ the IPOs average first-day returns in the previous three months.

Table 4. Descriptive statistics for rights issues regressions

\begin{tabular}{lcccccccccc}
\hline & \multicolumn{4}{c}{ Monthly Interval: 1987-2007 } & \multicolumn{5}{c}{ Quarterly Interval: 1987-2007 } \\
& Mean & Median & Std. Dev. & Max & Min & Mean & Median & Std. Dev. & Max & Min \\
\hline Num_Issues & 7.20 & 6.00 & 5.97 & 30.00 & 0.00 & 21.61 & 20.00 & 15.39 & 75.00 & 0.00 \\
\hline _BC & 0.86 & 1.00 & 0.34 & 1.00 & 0.00 & 0.86 & 1.00 & 0.34 & 1.00 & 0.00 \\
_CCI & 1.00 & 1.00 & 0.02 & 1.05 & 0.96 & 1.00 & 1.01 & 0.03 & 1.07 & 0.93 \\
_ $\Delta$ CCI (\%) & 0.01 & 0.55 & 0.05 & 1.50 & -1.50 & 0.01 & 0.06 & 0.45 & 1.45 & -1.43 \\
_ML & 1.16 & 1.17 & 0.17 & 1.63 & 0.61 & 1.16 & 1.17 & 0.17 & 1.63 & 0.61 \\
_MRun (\%) & 6.51 & 6.78 & 13.47 & 92.48 & -42.22 & 6.44 & 6.96 & 14.35 & 80.37 & -42.22 \\
__ 3bills (\%) & 0.03 & -0.28 & 6.50 & 43.53 & -18.66 & 0.22 & -0.29 & 11.75 & 54.50 & -35.16 \\
_GEYR & 2.12 & 2.15 & 0.38 & 3.39 & 1.11 & 2.11 & 2.14 & 0.37 & 3.26 & 1.13 \\
_DCEF & 10.06 & 9.96 & 1.74 & 23.11 & 2.44 & 14.20 & 12.74 & 7.31 & 34.49 & 2.48 \\
_MV (\%) & 93.08 & 80.44 & 42.43 & 311.20 & 42.89 & 91.84 & 80.06 & 40.58 & 301.37 & 43.42 \\
_AAPR (\%) & -1.47 & -1.06 & 5.17 & 24.34 & -34.29 & -1.47 & -1.06 & 5.59 & 24.34 & -34.29 \\
\hline
\end{tabular}


Note. Num_ Issues $=$ number of rights issues; _BC $=$ Business cycle dummy equals to one during periods of economic expansions and zero otherwise; _CCI= Consumer Confidence Index; $\_\Delta \mathrm{CCI}(\%)=$ percentage change in consumer confidence index $(\mathrm{CCI})$; $\_\mathrm{ML}=\mathrm{Market}$ level indicator, measured as the ratio of FTSE All-Share index relative to its 12-month moving average; _MRun= cumulative 6-month FTSE returns; $\_\Delta$ 3bills $(\%)=$ the percentage change in 3-month T-bill; _GEYR= gilt to equity yield ratio; _DCEF= the level of the average discounts on closed-end funds; _MV= the percentage 90-day market volatility, _AAPR $(\%)=$ the cumulative average abnormal returns in the previous three months.

\section{Results}

The empirical findings on the IPOs timing based on monthly and quarterly auto-regressive Poisson regressions are exhibited in Table 5 and 6 respectively. Overall, I find strongly significant evidence in support of adverse selection costs hypothesis, robust to the used data frequency and tested variables. The evidence also indicates that economic conditions, bull market timing and investor sentiment hypotheses are important determinants of IPOs timing, but of less significance and robustness. Specifically, the number of IPOs varies significantly with information asymmetry proxies, as stated with hypothesis $\mathrm{H}_{4}$. As shown, the 90-day market volatility exhibits robust adverse effect on the IPOs activity. Consistent with the information spill-over effect that realizes through the information generated about a set of pioneers going to the market and reduces uncertainty for the followers, and hence triggers more equity issues; the magnitude of the initial returns is positively and significantly related to the number of IPOs in the following quarter. These findings stand in line with Lowry and Schwert (2002) for US IPOs, and Michailides (2000) who has revealed positive, though insignificantly, results for UK IPOs.

In line with hypothesis $\mathrm{H}_{1}$, the empirical results also show strong support for the impact of the economic conditions on the IPOs activity. Business cycle dummy is significantly positive (at the 1-percent significance level). This is consistent with the UK-based findings on the economic business cycle reported by Michailides (2000). However, the findings on the impact of the other proxies for the economic climate, represented by the level and change consumer confidence index $(\mathrm{CCI})$, are found contradictory. While the findings generally exhibit a positive link between the number of IPOs and the lagged consumer confidence index (CCI) at the monthly interval, yet the quarterly regressions exhibit a negative, but insignificant, relation between the IPOs number and the change in consumer confidence index. Consistent with bull market timing hypothesis as stated by hypothesis $\mathrm{H}_{3}$, stock market variables, measured by the market level and market run-up, generally exert a positive influence on the IPOs activity. Market level, as represented by the ratio of FTSE All Shares relative to 3-year moving average, positively and significantly impact the IPOs activity. When the variable of "market run-up" (measured by cumulative market returns measured over 30,60 and 180 days) is used, the parameter is found significantly positive only for 180-day window (Note 8). The significance of stock market proxies that are measured for longer time windows appears in line with the IPO planning process that certainly exceeds a 30 and 60-day time period.

The findings on the impact of the cost of alternative sources of capital, proxied by the percentage change in 3-month T-Bills, are mixed depending on the time interval. Monthly regressions (Table 5) yield a negative impact on the number of IPOs, but quarterly regressions show positive effect (Tables 6) though both effects are insignificant. Likewise, the gilt to equity yield ratio (GEYR) exhibits mixed effects on the IPOs activity since it positively influences quarterly IPOs volume but with no statistical significance. However, it shows unexpectedly negative, but insignificant, impact when estimating monthly regressions. The above-mentioned findings on stock market proxies indicate that the number of IPOs varies significantly with the stock market valuation rather than with its relative valuation compared to other capital markets. Consistent with the behavioral timing hypothesis as stated in hypothesis $\mathrm{H}_{5}$, the discounts of closed-end funds (DCEFs) generally have a robustly negative significant effect.

Table 5. Auto-regressive poisson model of monthly IPOs volume, 1987-2007

\begin{tabular}{|c|c|c|c|c|c|c|c|c|}
\hline Model & 1 & 2 & 3 & 4 & 5 & 6 & 7 & 8 \\
\hline \multirow{2}{*}{ _Con. } & 0.13 & -8.57 & -0.82 & -9.48 & -9.09 & -8.45 & 0.13 & -0.03 \\
\hline & $(0.25)$ & $(-3.06)$ & $(-2.43)$ & $(-3.52)$ & $(-3.25)$ & $(-3.04)$ & -0.31 & $(-0.08)$ \\
\hline \multirow{2}{*}{ _ML } & 0.99 & 1.2 & 1.39 & 0.87 & & & & \\
\hline & (3.67) & $(5.16)$ & $(6.05)$ & $(3.43)$ & & & & \\
\hline _MRun(\%) & & & & & 1.55 & 1.86 & 1.05 & 1.18 \\
\hline
\end{tabular}




\begin{tabular}{|c|c|c|c|c|c|c|c|c|}
\hline _GEYR & $\begin{array}{c}-0.01 \\
(-0.06)\end{array}$ & & & $\begin{array}{c}0.26 \\
(1.54)\end{array}$ & & & $\begin{array}{c}0.48 \\
(3.04)\end{array}$ & $\begin{array}{c}0.45 \\
(2.87)\end{array}$ \\
\hline$\_\Delta$ 3bills(\%) & $\begin{array}{c}-0.29 \\
(-0.32)\end{array}$ & $\begin{array}{c}-0.75 \\
(-0.85)\end{array}$ & $\begin{array}{c}-0.83 \\
(-0.98)\end{array}$ & & $\begin{array}{c}-0.17 \\
(-0.19)\end{array}$ & $\begin{array}{c}-0.1 \\
(-0.11)\end{array}$ & & \\
\hline _DCEF & $\begin{array}{c}-0.22 \\
(-1.63)\end{array}$ & $\begin{array}{c}-0.4 \\
(-3.15)\end{array}$ & & $\begin{array}{c}-0.35 \\
(-2.63)\end{array}$ & $\begin{array}{c}-0.39 \\
(-2.92)\end{array}$ & & $\begin{array}{c}-0.29 \\
(-2.10)\end{array}$ & \\
\hline _BC & $\begin{array}{c}0.92 \\
(3.93)\end{array}$ & $\begin{array}{c}0.92 \\
(3.92)\end{array}$ & $\begin{array}{c}0.86 \\
(3.72)\end{array}$ & $\begin{array}{c}0.96 \\
(4.13)\end{array}$ & $\begin{array}{c}0.99 \\
(4.24)\end{array}$ & $\begin{array}{c}0.97 \\
(4.16)\end{array}$ & $\begin{array}{c}0.93 \\
(4.01)\end{array}$ & $\begin{array}{c}0.93 \\
(4.01)\end{array}$ \\
\hline${ }_{-} \mathrm{CCIt}_{4}$ & & $\begin{array}{c}8.28 \\
(2.97)\end{array}$ & & $\begin{array}{c}9.16 \\
(3.39)\end{array}$ & $\begin{array}{c}10 \\
(3.58)\end{array}$ & $\begin{array}{c}8.98 \\
(3.25)\end{array}$ & & \\
\hline _IPO Up (\%) & $\begin{array}{c}1.13 \\
(4.68)\end{array}$ & $\begin{array}{c}0.9 \\
(4.25)\end{array}$ & $\begin{array}{c}1.08 \\
(5.27)\end{array}$ & & $\begin{array}{c}0.91 \\
(4.34)\end{array}$ & $\begin{array}{c}0.94 \\
(4.54)\end{array}$ & & \\
\hline _MV (\%) & $\begin{array}{c}-0.39 \\
(-3.29)\end{array}$ & & & $\begin{array}{c}-0.28 \\
(-2.54)\end{array}$ & & & $\begin{array}{c}-0.36 \\
(-3.05)\end{array}$ & $\begin{array}{c}-0.42 \\
(-3.65)\end{array}$ \\
\hline _Trend & $\begin{array}{l}0.01 \\
(5.8)\end{array}$ & $\begin{array}{c}0.01 \\
(11.69)\end{array}$ & $\begin{array}{c}0.01 \\
(11.55)\end{array}$ & $\begin{array}{c}0.01 \\
(8)\end{array}$ & $\begin{array}{c}0.01 \\
(11.47)\end{array}$ & $\begin{array}{c}0.01 \\
(11.42)\end{array}$ & $\begin{array}{c}0.01 \\
(9.22)\end{array}$ & $\begin{array}{c}0.01 \\
(9.13)\end{array}$ \\
\hline _AC_M. & $\begin{array}{c}0.26 \\
(3.59)\end{array}$ & $\begin{array}{c}0.26 \\
(3.56)\end{array}$ & $\begin{array}{c}0.24 \\
(3.34)\end{array}$ & $\begin{array}{l}0.24 \\
(3.4)\end{array}$ & $\begin{array}{c}0.29 \\
(3.97)\end{array}$ & $\begin{array}{c}0.28 \\
(3.79)\end{array}$ & $\begin{array}{c}0.26 \\
(3.58)\end{array}$ & $\begin{array}{c}0.25 \\
(3.53)\end{array}$ \\
\hline _NA_M. & $\begin{array}{c}-0.62 \\
(-6.43) \\
\end{array}$ & $\begin{array}{c}-0.63 \\
(-6.38) \\
\end{array}$ & $\begin{array}{c}-0.63 \\
(-6.50) \\
\end{array}$ & $\begin{array}{c}-0.64 \\
(-6.61) \\
\end{array}$ & $\begin{array}{c}-0.61 \\
(-6.17) \\
\end{array}$ & $\begin{array}{c}-0.61 \\
(-6.14) \\
\end{array}$ & $\begin{array}{c}-0.63 \\
(-6.62) \\
\end{array}$ & $\begin{array}{c}-0.62 \\
(-6.50)\end{array}$ \\
\hline $\mathrm{R}^{2}(\%)$ & 66.60 & 65.20 & 65.90 & 65.80 & 64.70 & 64.80 & 66.10 & 66.20 \\
\hline
\end{tabular}

Note . Con.=Constant; _ML= Market level indicator, measured as the ratio of FTSE All-Share index relative to its 12-month moving average; _MRun $(\%)=$ cumulative 6-month FTSE returns;_GEYR= gilt to equity yield ratio;_ $\Delta$ 3bills $(\%)=$ the percentage change in 3-month T-bill; _DCEF $=$ the level of the average discounts on closed-end funds; $\mathrm{BC}=$ Business cycle dummy equals to one during periods of economic expansions and zero otherwise, ${ }_{-} \mathrm{CCI}_{-4}=$ the lagged value of the ratio of consumer confidence index $(\mathrm{CCI})$ to its 12 -month moving average;_IPO UP $(\%)=$ the IPOs average first-day returns in the previous three months; MV $(\%)=$ the percentage 90-day market volatility; _Trend = linear trend term; AC_M. = a seasonal dummy for active months, equal to 1 for March, June, July and December and zero otherwise; NA_M= a seasonal dummy for non-active months, equal to 1 for January, August and September and zero otherwise. T-statistics are in parenthesis.

Table 6. Auto-regressive poisson model of quarterly IPOs volume, 1987-2007

\begin{tabular}{|c|c|c|c|c|c|c|c|c|}
\hline Model & 1 & 2 & 3 & 4 & 5 & 6 & 7 & 8 \\
\hline \multirow[t]{2}{*}{ _Con. } & 0.99 & 0.92 & 0.10 & 0.50 & 1.50 & 1.64 & 1.65 & 1.46 \\
\hline & $(1.48)$ & $(1.74)$ & $(0.25)$ & $(0.83)$ & $(3.09)$ & $(6.01)$ & $(3.01)$ & $(2.71)$ \\
\hline \multirow[t]{2}{*}{ _ML } & 0.79 & 1.04 & 1.45 & 0.60 & & & & \\
\hline & $(2.12)$ & $(3.18)$ & $(5.45)$ & $(1.58)$ & & & & \\
\hline \multirow{2}{*}{ _MRun } & & & & & 1.71 & 2.05 & 0.86 & 1.06 \\
\hline & & & & & $(3.65)$ & $(4.36)$ & $(1.30)$ & $(1.54)$ \\
\hline \multirow{2}{*}{ _GEYR } & 0.13 & & & 0.48 & 0.28 & & 0.28 & 0.29 \\
\hline & $(0.62)$ & & & $(2.80)$ & $(1.64)$ & & $(1.44)$ & $(1.50)$ \\
\hline \multirow{15}{*}{$\_\Delta$ 3bills (\%) } & 0.16 & 1.06 & 1.02 & & & & 0.76 & \\
\hline & $(0.23)$ & $(1.74)$ & $(1.76)$ & & & & $(1.24)$ & \\
\hline & -0.01 & -0.03 & & 0.00 & -0.05 & & -0.02 & \\
\hline & $(-0.54)$ & $(-2.27)$ & & $(-0.25)$ & $(-3.98)$ & & $(-1.53)$ & \\
\hline & 0.89 & 0.85 & 0.86 & 0.84 & 0.81 & 0.86 & 0.85 & 0.90 \\
\hline & (3.01) & $(3.07)$ & (3.17) & $(2.83)$ & (3.03) & (3.05) & $(2.83)$ & $(2.98)$ \\
\hline & & -0.18 & & -0.23 & & & & \\
\hline & & $(-1.39)$ & & $(-1.68)$ & & & & \\
\hline & 0.87 & 0.98 & 0.80 & & 0.80 & 0.71 & 0.83 & 0.65 \\
\hline & (2.45) & $(3.55)$ & $(3.07)$ & & $(2.55)$ & $(2.74)$ & $(2.32)$ & $(1.88)$ \\
\hline & -0.56 & & & -0.68 & & & -0.53 & -0.61 \\
\hline & $(-2.84)$ & & & $(-3.67)$ & & & $(-2.37)$ & $(-3.24)$ \\
\hline & (5.99) & $(8.86)$ & $(10.25)$ & $(8.84)$ & $(7.31)$ & (9.89) & $(6.67)$ & 0.02 \\
\hline & 0.02 & 0.02 & 0.03 & 0.02 & 0.02 & 0.02 & 0.02 & $(6.89)$ \\
\hline & 78.3 & 81.1 & 80.7 & 78.3 & 81.7 & 78.9 & 77.4 & 77.6 \\
\hline
\end{tabular}


Note. Con.=Constant;_ML= Market level indicator, measured as the ratio of FTSE All-Share index relative to its 12-month moving average; _MRun $(\%)=$ cumulative 6-month FTSE returns;_GEYR= gilt to equity yield ratio;__ 3 bills $(\%)=$ the percentage change in 3 -month T-bill; _ $\mathrm{DCEF}=$ the level of the average discounts on closed-end funds; $\mathrm{BC}=$ Business cycle dummy equals to one during periods of economic expansions and zero otherwise,_CCI.4 = the lagged value of the ratio of consumer confidence index (CCI) to its 12 -month moving average; _IPO UP $(\%)=$ the IPOs average first-day returns in the previous three months; MV $(\%)=$ the percentage 90 -day market volatility; _Trend = linear trend term. T-statistics are in parenthesis.

When assessing the overall prediction power of the various timing regressions, it is clear that the auto-regressive Poisson models estimated using quarterly data outperform those that use monthly data. Quarterly regressions exhibit higher explanatory power, with $\mathrm{R}^{2}$ ranging from 77.4 percent to 81.7 percent, while for monthly regressions $\mathrm{R}^{2}$ ranges from 64.7 percent to 66.6 percent. This higher ability of quarterly regressions, compared to monthly regressions, in detecting the IPOs timing might be because of the length of IPOs planning and launching process that certainly exceeds a one-month time-span, so that any clustering of IPOs is likely to be apparent at the quarterly level more that the monthly level. However, it might be also because quarterly data are less noisy and volatile than monthly data. Finally, the strongly positive coefficient of 'linear trend term' across the various models shows that there is a long term upward drift in IPO activity over time, whilst the robustly significant findings on seasonal dummies are compelling with the time-series properties of IPOs series. As a diagnostic check, I obtain the Pearson residuals from all the auto-regressive Poisson models to check for autocorrelation. No autocorrelation has been detected (results are not reported here).

The results of rights issues regressions are presented in tables 7-8 At first glance, the determinants that appear to drive the timing of rights issues differ from those for IPOs, which indicates to the variation in the motives that drive the timing of the two events. Overall, the empirical evidence is mostly consistent with bull market timing hypothesis as indicated by $\mathrm{H}_{4}$. The behavioral timing hypothesis is not robustly supported, whilst the economic conditions and information asymmetry proxies generally exhibit inconsistent findings. Specially, the coefficients of stock market timing proxies, when measured by market level and market run-up, are consistently and robustly positive across different time intervals. The variable "market run-up" is found to be significantly positive, as shown in Tables 7-8. "Market level" variable exhibits positive, and generally significant, effect on rights issues.

The link between the gilt to equity yield ratio (GEYR) and rights issues volume is consistently positive and generally significant, but not robust. With respect to the percentage change in 3-month T-Bills, the findings show overall positive impact, as expected by bull market timing hypothesis, yet this impact is not significant. The proxy for investor sentiment measured by the discounts of closed-end funds (DCEFs) has consistently and significantly negative coefficients when quarterly auto-regressive Poisson are estimated but become inconsistently positive when using monthly regressions.

Unexpectedly, the empirical results appear conflicting with the economic conditions hypothesis. The parameter of economic cycle dummy has a negative, though insignificant, sign across different models. Similar findings have been shown for the variables of the level and change in consumer confidence index (CCI). Notably, this negative impact is robust to using other proxies for economic and business conditions such as retails sales index and short-run leading economic index (results of these variables not reported). Generally, these findings are in line with the negative correlations coefficients of economic conditions proxies, as reported in Appendix B, Tables B3 and B4. This indicates that seasoned firms appear to increase their rights offerings in coincidence with periods of unfavorable economic and business conditions. A possible explanation can be attributed to the issuing firms' need to raise new capital to satisfy short-needed liquidity, repay their debts and/or strengthen their balance sheets during these economic downturns.

With regard to the information asymmetry hypothesis, the findings provide a little evidence of the role of adverse-selection costs and market volatility in explaining the variations in the number of rights issues. In specific, the variables of adverse selection costs-measured by the abnormal announcement period returns for all the rights issues made in the last quarter-and market volatility, exhibit mixed and insignificant effects on the timing of rights issues. Specifically, the findings on the influence of abnormal announcement period returns on the issuance activity of rights issues are shown to be consistently, but insignificantly, positive under monthly and quarterly auto-regressive Possion models. The 90-day market volatility exhibits negative, though insignificant, effect under monthly auto-regressive Poisson are estimated, whilst it shows mixed findings when using quarterly auto-regressive Poisson regressions. So, firms appear to pay little attention to the prevailing degree of information asymmetry and uncertainty in the stock market when timing their rights offerings. the determinants that appear to drive the timing of rights issues differ from those for IPOs (i.e. while the issuance activity of IPOs seems to be mainly impacted by the information asymmetry-related factors, the issuance activity of rights issues 
is mostly affected by bull-market timing). This might be attributed to the fact that although IPOs and rights issues are the same corporate event (but at different times in a company's life), theoretically they can be motivated for different reasons based on assessing the relative advantages (benefits) and disadvantages (costs) associated with the offering. As a diagnostic check, I obtain the Pearson residuals from all the auto-regressive Poisson models to check for autocorrelation. No autocorrelation has been detected (results are not reported here).

Table 7. Auto-regressive poisson model of monthly rights issues volume, 1987-2007

\begin{tabular}{|c|c|c|c|c|c|c|c|c|}
\hline Model & 1 & 2 & 3 & 4 & 5 & 6 & 7 & 8 \\
\hline \multirow{2}{*}{ _Con. } & 0.41 & 3.51 & 1.04 & 1.80 & 2.61 & 2.43 & 0.91 & 1.22 \\
\hline & (1.34) & (2.54) & $(4.50)$ & $(1.27)$ & (1.92) & (1.79) & (3.75) & $(6.08)$ \\
\hline \multirow{2}{*}{ _ML } & 0.44 & 1.20 & 1.06 & 0.52 & & & & \\
\hline & (1.92) & $(6.08)$ & $(5.51)$ & (2.36) & & & & \\
\hline \multirow{2}{*}{ _MRun (\%) } & & & & & 2.23 & 2.25 & 1.98 & 1.92 \\
\hline & & & & & $(9.25)$ & (9.33) & (8.29) & $(9.32)$ \\
\hline \multirow{2}{*}{ _GEYR } & 0.57 & & & 0.54 & 0.37 & & 0.48 & 0.47 \\
\hline & (5.21) & & & $(4.96)$ & $(1.21)$ & & (5.23) & (5.19) \\
\hline \multirow{2}{*}{$\_\Delta$ 3bills (\%) } & 0.26 & 0.63 & 0.54 & & 0.36 & & & \\
\hline & $(0.80)$ & (1.98) & (1.69) & & (1.18) & & & \\
\hline \multirow{2}{*}{ _DCEF } & 0.22 & 0.26 & & 0.25 & 0.18 & & 0.26 & \\
\hline & (1.69) & (2.03) & & (1.85) & (1.44) & & (2.14) & \\
\hline \multirow{2}{*}{$\_$BC } & -0.11 & -0.04 & -0.05 & -0.07 & 0.13 & 0.13 & -0.03 & 0.01 \\
\hline & $(-1.47)$ & $(-0.5)$ & $(-0.67)$ & $(-0.94)$ & (1.71) & $(1.70)$ & $(-0.44)$ & $(0.12)$ \\
\hline \multirow{2}{*}{ _CCIt -4} & & -2.91 & & -1.48 & -0.79 & -0.44 & & \\
\hline & & $(-2.06)$ & & $(-1.03)$ & $(-0.58)$ & $(-0.32)$ & & \\
\hline \multirow{2}{*}{ _AAPR (\%) } & 1.05 & 0.75 & 0.99 & & 0.01 & 0.08 & & \\
\hline & (1.55) & (1.12) & $(1.47)$ & & $(0.02)$ & $(0.13)$ & & \\
\hline \multirow{2}{*}{ _MV (\%) } & -0.10 & & & -0.10 & & & -0.15 & -0.21 \\
\hline & $(-1.21)$ & & & $(-1.21)$ & & & $(-1.71)$ & $(-2.60)$ \\
\hline \multirow{2}{*}{ _Reg. } & -1.13 & -1.33 & -1.34 & -1.14 & -1.37 & -1.38 & -1.13 & -1.14 \\
\hline & $(-12.74)$ & $(-16.48)$ & $(-16.44)$ & $(-12.80)$ & $(-18.08)$ & $(-18.04)$ & $(-13.13)$ & $(-13.15)$ \\
\hline \multirow[t]{2}{*}{ _AC_M. } & 0.22 & 0.23 & 0.24 & 0.23 & 0.18 & 0.18 & 0.16 & 0.18 \\
\hline & $(3.80)$ & (4.01) & (4.13) & (4.05) & $(3.21)$ & (3.29) & (2.98) & $(3.21)$ \\
\hline \multirow[t]{2}{*}{ _NA_M. } & -0.34 & -0.32 & -0.32 & -0.34 & -0.32 & -0.32 & -0.35 & -0.35 \\
\hline & $(-5.21)$ & $(-4.95)$ & $(-4.94)$ & $(-5.28)$ & $(-5.03)$ & $(-5.04)$ & $(-5.57)$ & $(-5.49)$ \\
\hline $\mathrm{R} 2(\%)$ & 63.0 & 63.3 & 62.5 & 63.0 & 66.0 & 65.0 & 66.0 & 65.0 \\
\hline
\end{tabular}

Note. Con.=Constant;_ML= Market Level indicator, measured as the ratio of FTSE All-Share index relative to its 12-month moving average; _MRun $(\%)=$ cumulative 6-month FTSE returns;_GEYR= gilt to equity yield ratio; $\_$3bills $(\%)=$ the percentage change in 3 -month T-bill; _DCEF= the level of the average discounts on closed-end funds; $\mathrm{BC}=$ Business cycle dummy equals to one during periods of economic expansions and zero otherwise, _CCI-4= the lagged value of the ratio of consumer confidence index (CCI) to its 12-month moving average; volatility;_Reg. = Dummy variable accounting for regulatory change; AC_M. = a seasonal dummy for active months, equal to 1 for March, June, July and December and zero otherwise; NA_M= a seasonal dummy for non-active months, equal to 1 for January, August and September and zero otherwise. T-statistics are in parenthesis.

Table 8. Auto-regressive poisson model of quarterly UK rights issues volume, 1975-2007

\begin{tabular}{|c|c|c|c|c|c|c|c|c|}
\hline Model & 1 & 2 & 3 & 4 & 5 & 6 & 7 & 8 \\
\hline \multirow{2}{*}{ _Con. } & 1.39 & 2.11 & 1.80 & 1.27 & 2.13 & 3.11 & 1.93 & 1.88 \\
\hline & (3.73) & (6.48) & $(5.27)$ & (3.47) & (7.71) & (9.91) & $(6.94)$ & (6.44) \\
\hline \multirow{2}{*}{ _ML } & 0.76 & 1.41 & 1.30 & 0.89 & & & & \\
\hline & $(2.30)$ & $(5.00)$ & $(4.55)$ & (2.79) & & & & \\
\hline \multirow{2}{*}{ _MRun (\%) } & & & & & 1.53 & 1.90 & 1.85 & 1.84 \\
\hline & & & & & (4.65) & (5.47) & $(5.72)$ & (5.63) \\
\hline \multirow{2}{*}{ _GEYR } & 0.66 & & & 0.62 & 0.70 & & 0.68 & 0.55 \\
\hline & (4.11) & & & (3.89) & (5.42) & & (5.43) & (4.26) \\
\hline
\end{tabular}




\begin{tabular}{|c|c|c|c|c|c|c|c|c|}
\hline$\_\Delta$ 3bills (\%) & $\begin{array}{c}-0.05 \\
(-0.17)\end{array}$ & $\begin{array}{c}0.20 \\
(0.66)\end{array}$ & $\begin{array}{c}0.12 \\
(0.42)\end{array}$ & & & $\begin{array}{c}0.27 \\
(0.96)\end{array}$ & & \\
\hline _DCEF & $\begin{array}{c}-0.04 \\
(-5.64)\end{array}$ & $\begin{array}{c}-0.03 \\
(-5.50)\end{array}$ & & $\begin{array}{c}-0.04 \\
(-5.56)\end{array}$ & $\begin{array}{c}-0.03 \\
(-6.29)\end{array}$ & & $\begin{array}{c}-0.04 \\
(-6.72)\end{array}$ & \\
\hline _BC & $\begin{array}{l}-0.12 \\
(-1.10)\end{array}$ & $\begin{array}{c}-0.09 \\
(-0.87)\end{array}$ & $\begin{array}{c}-0.09 \\
(-0.85)\end{array}$ & $\begin{array}{c}-0.11 \\
(-1.01)\end{array}$ & $\begin{array}{c}-0.06 \\
(-0.60)\end{array}$ & $\begin{array}{c}0.04 \\
(0.39)\end{array}$ & $\begin{array}{c}-0.05 \\
(-0.46)\end{array}$ & $\begin{array}{c}-0.10 \\
(-1.02)\end{array}$ \\
\hline _CCIt.4 $_{-4}$ & & $\begin{array}{c}0.05 \\
(0.56)\end{array}$ & & $\begin{array}{c}0.01 \\
(0.06)\end{array}$ & & & & \\
\hline _AAPR (\%) & $\begin{array}{c}1.44 \\
(1.53)\end{array}$ & $\begin{array}{c}1.34 \\
(1.47)\end{array}$ & $\begin{array}{c}1.48 \\
(1.60)\end{array}$ & & $\begin{array}{c}0.80 \\
(0.94)\end{array}$ & $\begin{array}{c}1.21 \\
(1.35)\end{array}$ & & \\
\hline _MV (\%) & $\begin{array}{c}0.16 \\
(1.11)\end{array}$ & & & $\begin{array}{c}0.15 \\
(1.03)\end{array}$ & & & $\begin{array}{c}0.33 \\
(2.31)\end{array}$ & $\begin{array}{c}0.08 \\
(0.61)\end{array}$ \\
\hline _Reg. & $\begin{array}{c}-1.10 \\
(-9.21)\end{array}$ & $\begin{array}{c}-1.28 \\
(-11.96)\end{array}$ & $\begin{array}{c}-1.11 \\
(-10.27)\end{array}$ & $\begin{array}{c}-1.09 \\
(-9.05)\end{array}$ & $\begin{array}{c}-1.07 \\
(-10.08)\end{array}$ & $\begin{array}{c}-1.17 \\
(-11.94)\end{array}$ & $\begin{array}{c}-1.12 \\
(-10.58)\end{array}$ & $\begin{array}{c}-0.92 \\
(-8.59)\end{array}$ \\
\hline _AC_Q. & $\begin{array}{c}0.32 \\
(3.92)\end{array}$ & $\begin{array}{c}0.30 \\
(3.73)\end{array}$ & $\begin{array}{c}0.29 \\
(3.57)\end{array}$ & $\begin{array}{c}0.34 \\
(4.24)\end{array}$ & $\begin{array}{c}0.28 \\
(3.82)\end{array}$ & $\begin{array}{c}0.27 \\
(3.43)\end{array}$ & $\begin{array}{c}0.30 \\
(4.30)\end{array}$ & $\begin{array}{c}0.29 \\
(4.04)\end{array}$ \\
\hline $\mathbf{R}^{2}(\%)$ & 70.9 & 71.5 & 69.7 & 69.7 & 75.3 & 72.7 & 76.2 & 74.8 \\
\hline
\end{tabular}

Note. Con.= Constant; $\_$ML= Market Level indicator, measured as the ratio of FTSE All-Share index relative to its 12-month moving average; _MRun $(\%)=$ cumulative 6-month FTSE returns;_GEYR= gilt to equity yield ratio;_ $\Delta$ bills $(\%)=$ the percentage change in 3-month T-bill; _DCEF $=$ the level of the average discounts on closed-end funds; $\mathrm{BC}=$ Business cycle dummy equals to one during periods of economic expansions and zero otherwise,_CCI-4= the lagged value of the ratio of consumer confidence index (CCI) to its 12-month moving average; $\operatorname{AAPR}(\%)=$ the cumulative average abnormal returns in the previous three months; $\mathrm{MV}(\%)=$ the percentage 90 -day market volatility; _Reg. = Dummy variable accounting for regulatory change; _AC_Q.= a seasonal dummy for active quarter equal to 1 in the second calendar quarter of each year and zero otherwise. T-statistics are in parenthesis.

\section{Summary and Conclusion}

This study aimes to address a number of questions related to the timing of IPOs and right issues in the UK: when do firms decide to go to the market? What drive the determinants of this decision? Do firms issue more equity during favorable economic conditions? Do firms take advantage of periods of investor over-optimism and windows of opportunity? Do firms just take advantage of attractive stock prices? Or are firms being triggered by reduced adverse selection costs increase their equity offerings? Are the times when firms going to the market for the first time (IPOs) different for subsequent times (rights issues)?

The answers for UK IPOs are robustly consistent with the adverse selection story; firms tend to make more flotations during periods of reduced asymmetric information and market uncertainty. The market volatility and level of under-pricing show consistent and significant results, robust to the data frequency and variables tested. The findings also exhibit evidence in support of the favorable economic conditions, bull market timing and investor sentiment hypotheses, but of less significance and robustness. Business cycle dummy shows robustly significant positive effect, in contrast to the consumer confidence index (CCI) that shows mixed effects. In line with the bull market timing hypothesis, the variables of 'market level' and 'market run-up' overall exert consistently positive influence on the IPOs activity. This stands in line with Rydqvist and Hogholm (1995), Rees (1997), Michailide (2000), Pastor and Veronesi (2005), and Burgstaller (2008). However, other proxies for stock market conditions, represented by the percentage change in 3-month T-Bills and GEYR, exhibit mixed effects on the IPOs activity. The findings on the influence of the investor sentiment proxy, represented by DCEFs, on the IPOs volume are significantly negative.

For rights issues, the timing story appears different. In general, UK seasoned firms tend to time their offerings mostly during periods of bull stock prices, supporting the UK findings of Michailides (2000). Overall, the coefficients of market level and market run-up variables are consistently and robustly positive across different time intervals. The proxy for investor sentiment measured by DCEFs has consistently and significantly negative coefficients only when quarterly auto-regressive Poisson are estimated but become inconsistently positive otherwise. By contrast, the economic conditions generally exhibit inconsistent findings. Unexpectedly, the findings on economic conditions proxies (economic cycle dummy and consumer confidence index (CCI)) exhibit negative, though insignificant, effects across different models, which indicates that issuing firms might need to raise new capital to satisfy short-needed liquidity, repay their debts and/and strengthen their balance sheets during these economic downturns. Also, adverse selection proxies, represented by the abnormal announcement period returns for all the rights issues made in the last quarter and market volatility, exhibit mixed and 
insignificant effects on timing of rights issues. Finally, it is found that the regulatory changes made in the UK SEOs market in 1996 dramatically affect the rights issues activity in the UK thereafter. This difference might be attributed to the fact that although IPOs and rights issues are the same corporate event (but at different times in a company's life), theoretically they can be motivated for different reasons based on assessing the relative advantages (benefits) and disadvantages (costs) associated with the offering.

\section{References}

Aggarwal, R., \& Rvoli, P. (1990). Fads in the initial public offering market? Financial Management, 19(4), 45-57. http://dx.doi.org/10.2307/3665609

Alti, A. (2005). IPO market timing. Review of Financial Studies, 18(3), 1105-1138. http://dx.doi.org/10.1093/rfs/hhi022

Alti, A. (2006). How persistent in the impact of market timing on capital structure. Journal of Finance, 61(4), 1681-1710. http://dx.doi.org/10.1111/j.1540-6261.2006.00886.x

Bayless, M., \& Jay, N. (2003). Is the performance of firms following seasoned equity issues anomalous? Journal of Banking and Finance, 27(7), 1273-1296. http://dx.doi.org/10.1016/S0378-4266(02)00257-1

Benninga, S., Helmantel, M., \& Sarig, O. (2005). The timing of initial public offerings. Journal of Financial Economics, 75(1), 115-132. http://dx.doi.org/10.1016/j.jfineco.2003.04.002

Bleaney, M. (2000). Investor sentiment, discounts and returns on closed-end funds. Discussion paper in Economics, University Of Nottingham.

Brau, J., \& Fawcett, S. (2006). Initial public offerings: An analysis of theory and practice. Journal of Finance, 61(1), 399-436. http://dx.doi.org/10.1111/j.1540-6261.2006.00840.x

Breinlinger, L., \& Glogova, E. (2002). Determinants of initial public offerings: A European time-series cross-section analysis. Financial Stability Report 3, Oesterreichische National bank, Vienna.

Burgstaller, J. (n. d.). When and why do Austrian companies issue shares? Empirica, 36(3), 229-244.

Campbell, C., Du, Y., Rhee, S., \& Tang, N. (2008). Market sentiment, IPO under-pricing, and valuation. FMA Annual Meeting, Reno, USA.

Chen, A., \& Chen, L. (2008). Seasoned equity offerings, market timing and long-run performance. Working Paper. Retrieved from http://fin.shu.edu.tw/word/conference/2008conference/paper/2-B1.pdf

Chiu, H. (2005). Investor preferences, mutual fund flows, and the timing of IPO. Working paper, Chapman University.

Choe, H., Masulis, R., \& Nanda, V. (1993). Common stock offerings across the business cycle: Theory and evidence. Journal of Empirical Finance, 1(1), 3-33. http://dx.doi.org/10.1016/0927-5398(93)90003-A

Cook, D., Jarrel, S., \& Kieschnick, R. (2003). Investor sentiment and IPO cycles. Working paper, University of Texas.

Dierkens, N. (1991). Information asymmetry and equity issues. Journal of Finance and Quantitative Analysis, 26(2), 181-198. http://dx.doi.org/10.2307/2331264

Gemmill, G., \& Thomas, D. (2002). Noise-trading, costly arbitrage, and asset prices: Evidence from closed-end funds. Journal of Finance, 57(6), 2571-2594. http://dx.doi.org/10.1111/1540-6261.00506

Gerbich, M. (1996). The timing and performance of initial public offerings: Insights from securitized real estate new issues (Unpublished doctoral dissertation). City University.

Gregory, A., Guermat, C., \& Al-Shawawreh, F. (2010). UK IPOs: Long run returns, behavioural timing and pseudo timing. Journal of Business Finance and Accounting, 37(5-6), 612-647. http://dx.doi.org/10.1111/j.1468-5957.2010.02182.x

Harjoto, M., \& Garen, J. (2003). Why do IPO firms conduct primary seasoned equity offerings? Financial Review, 38(1), 103-125. http://dx.doi.org/10.1111/1540-6288.00037

Harris, R., \& René, S. (2000). The gilt-equity yield ratio and the predictability of UK and US equity returns. Journal of Business Finance and Accounting, 27(3), 333-357. http://dx.doi.org/10.1111/1468-5957.00316

Helwege, J., \& Liang, N. (2004). Initial public offerings in hot and cold markets. Journal of Financial and Quantitative Analysis, 39(3), 541-569. http://dx.doi.org/10.1017/S0022109000004026

Hoechle, D., \& Schmid, M. (2007). Which, why, and for how long do IPOs underperforms? Working Paper, 
University of Basel.

Hoffmann-Burchardi, U. (2001). Clustering of initial public offerings, information revelation and underpricing. European Economic Review, 45(2), 353-383. http://dx.doi.org/10.1016/S0014-2921(00)00053-2

Ibbotson, R., Sindelar, J., \& Ritter, J. (1994). The market's problems with the pricing of initial public offerings. Journal of Applied Corporate Finance, 7(1), 66-74. http://dx.doi.org/10.1111/j.1745-6622.1994.tb00395.x

Korajczyk, R., Lucas, D., \& McDonald, R. (1988). The Effect on information releases on the pricing and timing of equity issues: Theory and evidence. Working paper, Kellogg School of Management, Northwestern University.

Lee, C., Myers, J., \& Swaminathan, B. (1999). What is the intrinsic value of the Dow? Journal of Finance, 54(5), 1693-1741. http://dx.doi.org/10.1111/0022-1082.00164

Ljungqvist, A. (1995). The timing, pricing and long-term performance of initial public offerings (Unpublished doctoral dissertation). Nuffield College, Oxford University

Ljungqvist, A. (2006). IPO Under-pricing: A survey. In E. Eckbo (Ed.), Handbook in corporate finance: Empirical corporate finance (pp. 375-418). New York: Elsevier.

Long, J. (1997). Regression models for categorical and limited dependent variables. Thousand Oaks, CA: Sage Publications.

Lowry, M. (2003). Why does IPO volume fluctuate so much? Journal of Financial Economics, 67(1), 3-40. http://dx.doi.org/10.1016/S0304-405X(02)00230-1

Lowry, M., \& Schwert, W. (2002). IPO market cycles: bubbles or sequential learning? Journal of Finance, 57(3), 1171-1200. http://dx.doi.org/10.1111/1540-6261.00458

Migiakis, P., \& Bekiris, F. (2009). Regime switches between dividend and bond yields. International Review of Financial Analysis, 18(4), 198-204. http://dx.doi.org/10.1016/j.irfa.2009.03.008

Mikkelson, W., Partch, M., \& Shah, K. (1997). Ownership and operating performance of companies that go public. Journal of Financial Economics, 44(3), 281-307. http://dx.doi.org/10.1016/S0304-405X(97)00006-8

Myers, S., \& Majluf, N. (1984). Corporate financing and investment decision when firms have information investors do not have. Journal of Financial Economics, 13(2), 187-221. http://dx.doi.org/10.1016/0304-405X(84)90023-0

Pastor, L., \& Veronesi, P. (2003). Stock valuation and learning about profitability. Journal of Finance, 58(5), 1749-1789. http://dx.doi.org/10.1111/1540-6261.00587

Purnanandam, A., \& Swaminathan, B. (2004). Are IPOs really underpriced? Review of Financial Studies, 17(3), 811-848. http://dx.doi.org/10.1093/rfs/hhg055

Qian, H. (2005). Timing of seasoned equity offerings: A duration analysis. Working paper, Pennsylvania State University.

Rajan, R., \& Servaes, H. (1997). Analyst following of initial public offerings. Journal of Finance, 52(2), 507-529. http://dx.doi.org/10.1111/j.1540-6261.1997.tb04811.x

Rau, P., \& Stouraitis, A. (2011). Patterns in the timing of corporate event waves. Journal of Financial and Quantitative Analysis, 46(1), 209-246. http://dx.doi.org/10.1017/S0022109010000694

Rees, W. (1997). The arrival rate of initial public offerings in the UK. European Financial Management, 3(1), 45-62. http://dx.doi.org/10.1111/1468-036X.00030

Ritter, J., \& Welch, I. (2002). A review of IPO activity, pricing, and allocations. Journal of Finance, 57(4), 1795-1828. http://dx.doi.org/10.1111/1540-6261.00478

Rydqvist, K., \& Hoghölm, K. (1995). Going public in the 1980s: Evidence from Sweden. European Financial Management, 1(3), 287-315. http://dx.doi.org/10.1111/j.1468-036X.1995.tb00021.x

Taylor, K., \& McNabb, R. (2007). Business cycles and the role of confidence: Evidence for Europe. Oxford Bulletin of Economics and Statistics, 69(2), 185-208. http://dx.doi.org/10.1111/j.1468-0084.2007.00472.x

Wagner, H. (2007). Public equity issues and the scope for market timing. Working paper, London Business School.

Yongyuan, Q. (2008). Analysis into IPO under-pricing and clustering in Hong Kong equity market. Working paper, University Library of Munich. 
Yung, C., Colak, G., \& Wang, W. (2008). Cycles in the IPO market. Journal of Financial Economics, 89(1), 192-208. http://dx.doi.org/10.1016/j.jfineco.2007.06.007

\section{Notes}

Note 1. With regard to rights issues, Michailides' (2000) study period dates from 1975 and finishes in 1996, after which the relative number of firms conducting rights issues has dramatically declined due to the regulatory change in 1996, and so the overall view of UK right issues has noticeably changed. By examining UK rights issues lunched from 1975 to 2007, my study will examine whether and how these regulatory changes affect timing of rights issues.

Note 2. To address the robustness of the results, I replicate the timing regression analysis using the OLS method, using Newey-West procedure to produce standard errors corrected for heteroskedasticity and autocorrelation (Newey \& West, 1987). Results are not reported in this study.

Note 3. In addition to directly investigating the impact of suggested investor sentiment proxies on the timing of IPOs and SEOs, there is another empirical approach based on the scrutiny of post-issue performance of the IPOs and SEOs and how this performance is impacted by the degree of mis-valuation, such as Rajan and Servaes (1997), Helwege and Liang (2004), Purnanandam and Swaminathan (2004), Hoechle and Schmid (2007) and Campbell, Du, Rhee, and Tang (2008).

Note 4. At monthly level, there are significantly more IPOs in March, June, July and December. By contrast, January, August and September frequently exhibit a fewer number of IPO-issuing firms going to the market. On the other hand, rights issues tend to substantially increase during March, May, June and July, and fall in January, February, August and December. For IPOs and rights issues, higher activity in months, such as March, May, June and July, appears consistent with firms' tendency to go to the market around their quarterly, semi-yearly and yearly earnings announcements, while firms' tendency to offer fewer issues in months, such as January, February, August, September and December, appears to coincide with seasonal factors such as vacations (summer and Christmas holiday).

Note 5. For UK rights issues, the long-run trend is less obvious, and so it will be excluded from the regressions of rights issues.

Note 6. The Conference Board has produced the main indexes of cyclical activity for the US since 1995, when it was selected by the US Department of Commerce's Bureau of Economic Analysis (BEA) to assume responsibility for constructing the three composite (leading, coincident, and lagging) indexes (Business Cycle Indicators Handbook, 2001).

Note 7. A closed-end fund (CEF) is a mutual fund with a limited number of publicly traded shares. The share price of it is comprised of the value of the investments in the fund (net asset value (NAV)), and of the premium (or discount) placed by the market, and so closed-end fund shares typically sell at prices not equal to the per-share market value of the fund assets (NAV). If the fund's share price is higher than per share NAV it is said to be traded at a premium; when it is lower, it is traded at a discount. According to behavioural finance theories, demand for CEFs is more likely to increase during periods of investor over-optimism, which will negatively affect the absolute value of the discounts. Indeed, this argument appears difficult to apply in the UK closed-end fund market as it is largely dominated by institutional investors rather than irrational individual investors. Nonetheless, UK-based studies show similar results to the US closed-end fund market even though the UK closed-end fund market is denominated by institutional investors. For instance, Gemmill and Thomas (2002), making use of a sample of 158 UK closed-end funds, find that the changes in discounts are associated with time-varying noise-trader sentiment. Consistently, Bleaney (2000, p. 21) states that "institutional involvement in the market for closed-end funds in the U.K. is substantial (individuals own only about 50 percent of the shares), yet the market seems to be as strongly characterized by noise trader effects as in the U.S.".

Note 8. Only the "market run-up" for 180 days is reported

\section{Appendix A}

\section{An Alternative Model: Auto-Regressive Poisson Regression}

IPOs and rights issues data show particular features related to (i) its non-negative count nature, and to (ii) its time-series properties. A successful model for such series should take both of these features into account. The non-negative count nature of IPOs and SEOs volume is most appropriately captured by the Poisson Model, then 
the model will be extended to capture the time-series properties, as follows: In a Poisson regression, the outcome is described by a conditional mean which is an exponential linear combination of $\mathrm{X}$ (i.e. $\mathrm{E}(\mathrm{Y} \mid \mathrm{X})=\exp (\mathrm{X} \beta)$ ). In more detail, let $\left\{\mathrm{y}_{\mathrm{t}}\right\}$ be a series of observations on a random variable $\mathrm{Y}$, with $\mathrm{t}=1,2, . ., \mathrm{T}$, and let $\mathrm{X}$ be the TxK matrix of $\mathrm{K}$ explanatory variables. If the dependent variable $\left\{\mathrm{y}_{\mathrm{t}}\right\}$ has independent Poisson distribution with parameter $\lambda_{t}$ (which is equal to the mean and variance), then

$$
\operatorname{Pr}\left(Y=y_{t}\right)=\frac{e^{-\lambda_{t}} \lambda_{t}^{y_{t}}}{y_{t} !}
$$

By assuming - as standard $-\left\{\lambda_{\mathrm{t}}\right\}$ is log-linearly dependent on $\mathrm{X}$ (i.e. $\ln \lambda_{\mathrm{t}}=\mathrm{X} \beta_{\mathrm{t}}$ ) and so ruling out negative means, the likelihood function becomes:

$$
L=\prod_{t=1}^{T} \frac{e^{-\lambda_{t}} \lambda_{t}^{y_{t}}}{y_{t} !}=e^{-\sum \lambda_{t}} \prod_{t=1}^{T} \frac{e^{y_{t} \ln \lambda_{t}}}{y_{t} !}=\frac{e^{\sum\left(-\lambda_{t}+y_{t} \ln \lambda_{t}\right)}}{\prod_{t=1}^{T}\left(y_{t} !\right)}
$$

And thus the log-likelihood is

$$
L=\ln L=-\sum_{t=1}^{T} \lambda_{t}+\sum_{t=1}^{T} y_{t} \ln \lambda_{t}-\sum_{t=1}^{T} \ln \left(y_{t} !\right)
$$

This function can be then maximised with respect of $\beta$ (Eq.4) and then iterative weighted least squares (IWLS) can be used to solve it and estimate $\beta$ :

$$
\frac{\partial L}{\partial \beta}=\sum_{t=1}^{T} x_{t}\left(y_{t}-\lambda_{t}\right)
$$

As Poisson model explicitly assumes, the mean is equal to variance (equal to $\lambda$ ), and $\{y t\}$ are independently distributed, which are more expected to be violated when modelling time-series data. There is therefore a need to adjust for potential autocorrelation and over-dispersion. As such, I employ a log-linear model using auto-regressive Poisson model, as developed by Katsouyanni et al. (1996) and Schwartz et al. (1996), as it flexibly allows for both issues.

This involves initially estimating a standard Poisson regression model then incorporating the resulting residuals into the model's subsequent iteration, in addition to allowing for the dispersion of the dependent variable (i.e. $\mathrm{E}(\mathrm{yt})=\exp \left(\sum \beta \mathrm{Xt}-\tau\right)=\lambda \mathrm{t}$ with $\left.\operatorname{var}(\mathrm{yt})=\alpha \lambda \mathrm{t}\right)$. In practise, I employ a standard Poisson model to obtain the Pearson residuals to check for the order of autocorrelation, according to which the order of the auto-regressive models will be specified.

\section{Appendix B}

\section{Correlation Coefficients for UK IPOs and Rights Issues}

At first glance, it is clear from the correlations coefficients between IPOs volume and explanatory variables that the findings are consistent overall with the investor sentiment and adverse selection hypotheses, while partially supporting the economic conditions and bull market timing hypotheses. For rights issues, four proxies for bull market timing show consistent (positive) correlations while economic conditions proxies exhibit mixed findings. Adverse selection costs proxies are also slightly supported. As expected, the dummy variable that represents the

\begin{tabular}{|c|c|c|c|c|c|c|c|c|c|c|c|c|}
\hline & N_IPOs & ML. & MRun & GEYR & $\Delta$ 3bills & DCEF & BC & CCIt-4 & MV & IPO Up (\%) & Trend & AC_M. NA_M. \\
\hline N_IPOs & 1.00 & & & & & & & & & & & \\
\hline ML & 0.21 & 1.00 & & & & & & & & & & \\
\hline MRun & 0.16 & 0.64 & 1.00 & & & & & & & & & \\
\hline GEYR & -0.27 & 0.47 & 0.29 & 1.00 & & & & & & & & \\
\hline$\Delta 3$ bills & -0.36 & 0.15 & 0.08 & 0.56 & 1.00 & & & & & & & \\
\hline DCEF & -0.16 & -0.20 & -0.33 & -0.06 & -0.02 & 1.00 & & & & & & \\
\hline BC & 0.30 & 0.09 & 0.03 & -0.10 & -0.48 & 0.03 & 1.00 & & & & & \\
\hline CCIt-4 & 0.11 & 0.14 & 0.05 & 0.13 & -0.16 & 0.13 & 0.01 & 1.00 & & & & \\
\hline MV & -0.23 & -0.40 & -0.58 & -0.13 & -0.09 & 0.27 & 0.07 & -0.03 & 1.00 & & & \\
\hline IPO Up (\%) & 0.27 & 0.18 & 0.15 & 0.20 & -0.16 & -0.09 & 0.23 & 0.19 & 0.06 & 1.00 & & \\
\hline
\end{tabular}
institutional change in the UK SEOs market after 1996 shows a strong negative correlation with the number of rights issues.

Table B1. Pearson correlation coefficients for monthly IPOs, 1987-2007 


\begin{tabular}{cccccccccccccc}
\hline Trend & 0.50 & -0.20 & -0.10 & -0.78 & -0.76 & 0.06 & 0.33 & -0.04 & 0.01 & 0.10 & 1.00 & \\
AC_M. & 0.24 & 0.02 & 0.02 & 0.01 & 0.00 & 0.05 & 0.00 & 0.00 & -0.01 & -0.02 & 0.00 & 1.00 & \\
NA_M. & -0.30 & -0.01 & -0.02 & 0.00 & 0.02 & 0.00 & 0.00 & 0.01 & 0.00 & -0.03 & 0.00 & -0.41 & 1.00 \\
\hline
\end{tabular}

Note. N_IPOs = number of IPOs per month; $\mathbf{M L}=$ the ratio of FTSE All-Share index relative to its 12-month moving average; MRun = cumulative 6-month FTSE returns; GEYR= gilt to equity yield ratio; $\Delta \mathbf{3 b i l l s}=$ the percentage change in 3-month T-bill; $\mathbf{D C E F}=$ the level of the average discounts on closed-end funds: $\mathbf{B C}=$ Business cycle dummy equals to one during periods of economic expansions and zero otherwise; $\mathbf{C C I}_{\mathbf{t}-4}=$ the lagged value of the ratio of consumer confidence index (CCI) to its 12-month moving average; $\mathbf{M V}=$ the 90 -day market volatility expressed as a percentage; IPO Up $(\boldsymbol{\%})=$ the average first-day returns of all the IPOs launched in the previous three months; Trend = linear trend term; $\mathbf{A C} \_\mathbf{M} .=$ a seasonal dummy, equal to 1 and zero otherwise, for March, June, July and December; and NA_M.= a seasonal dummy, equal to 1 and zero otherwise, for January, August and September.

Table B2. Pearson correlation coefficients for quarterly IPOs, 1987-2007

\begin{tabular}{|c|c|c|c|c|c|c|c|c|c|c|c|}
\hline & N_IPOs & ML & MRun & GEYR & $\Delta$ 3bills & DCEF & BC & $\mathrm{CCI}_{\mathrm{t}-4}$ & MV & IPO Up (\%) & Trend \\
\hline N_IPOs & 1.00 & & & & & & & & & & \\
\hline ML & 0.24 & 1.00 & & & & & & & & & \\
\hline MRun & 0.18 & 0.62 & 1.00 & & & & & & & & \\
\hline GEYR & -0.25 & 0.46 & 0.28 & 1.00 & & & & & & & \\
\hline$\Delta$ 3bills & 0.22 & 0.15 & 0.10 & 0.19 & 1.00 & & & & & & \\
\hline DCEF & -0.34 & -0.29 & -0.20 & 0.20 & -0.07 & 1.00 & & & & & \\
\hline BC & 0.36 & 0.08 & 0.08 & -0.07 & 0.19 & -0.04 & 1.00 & & & & \\
\hline $\mathbf{C C I}_{\mathrm{t}-4}$ & -0.03 & 0.01 & -0.06 & 0.05 & 0.13 & -0.19 & -0.13 & 1.00 & & & \\
\hline MV & -0.27 & -0.42 & -0.57 & -0.13 & -0.16 & 0.56 & 0.08 & -0.06 & 1.00 & & \\
\hline IPO Up (\%) & 0.32 & 0.16 & 0.21 & 0.30 & 0.11 & 0.19 & 0.23 & -0.06 & 0.00 & 1.00 & \\
\hline Trend & 0.60 & -0.21 & -0.10 & -0.70 & 0.04 & -0.32 & 0.33 & 0.04 & 0.06 & 0.10 & 1.00 \\
\hline
\end{tabular}

Note. N_IPOs = number of IPOs per month; $\mathbf{M L}=$ the ratio of FTSE All-Share index relative to its 12 -month moving average; MRun = cumulative 6-month FTSE returns; GEYR= gilt to equity yield ratio; $\Delta \mathbf{3 b i l l s}=$ the percentage change in 3-month T-bill; DCEF = the level of the average discounts on closed-end funds: $\mathbf{B C}=$ Business cycle dummy equals to one during periods of economic expansions and zero otherwise; $\mathbf{C C I}_{\mathbf{t}-4}=$ the lagged value of the ratio of consumer confidence index (CCI) to its 12-month moving average; $\mathbf{M V}=$ the 90 -day market volatility expressed as a percentage; IPO Up $(\%)=$ the average first-day returns of all the IPOs launched in the previous three months; Trend $=$ linear trend term.

Table B3. Pearson correlation coefficients for monthly rights issues, 1975-2007

\begin{tabular}{|c|c|c|c|c|c|c|c|c|c|c|c|c|c|}
\hline & N_Issues & ML & MRun- & GEYR & $\Delta$ 3bills & DCEF & BC & CCIt-4 & $\operatorname{AAPR}(\%)$ & MV & Reg. & AC_M & NA_M \\
\hline N_Issues & 1.00 & & & & & & & & & & & & \\
\hline ML & 0.27 & 1.00 & & & & & & & & & & & \\
\hline MRun & 0.44 & 0.40 & 1.00 & & & & & & & & & & \\
\hline GEYR & 0.49 & 0.52 & 0.26 & 1.00 & & & & & & & & & \\
\hline$\Delta$ 3bills & 0.07 & -0.05 & 0.05 & 0.05 & 1.00 & & & & & & & & \\
\hline DCEF & 0.06 & -0.14 & -0.07 & -0.04 & 0.02 & 1.00 & & & & & & & \\
\hline BC & -0.13 & 0.16 & -0.12 & -0.01 & 0.05 & 0.04 & 1.00 & & & & & & \\
\hline $\mathrm{CCI}_{\mathrm{t}-\mathbf{4}}$ & -.0044 & 0.10 & -0.11 & 0.00 & 0.13 & 0.15 & 0.26 & 1.00 & & & & & \\
\hline $\operatorname{AAPR}(\%)$ & 0.09 & 0.24 & 0.27 & 0.02 & 0.09 & 0.05 & 0.11 & -0.03 & 1.00 & & & & \\
\hline Vol. & -0.05 & -0.37 & -0.01 & -0.03 & -0.08 & 0.04 & -0.12 & -0.09 & -0.09 & 1.00 & & & \\
\hline Reg. & -0.59 & -0.31 & -0.19 & -0.61 & -0.01 & 0.02 & 0.27 & -0.01 & 0.00 & 0.06 & 1.00 & & \\
\hline AC_M. & -0.26 & 0.02 & -0.09 & 0.01 & -0.06 & -0.08 & 0.00 & 0.00 & -0.10 & 0.04 & 0.00 & 1.00 & \\
\hline NA_M. & 0.28 & 0.03 & 0.19 & 0.05 & 0.06 & 0.11 & 0.00 & -0.01 & 0.19 & -0.04 & 0.00 & -0.50 & 1.00 \\
\hline
\end{tabular}

Note. Num_ Issues= number of rights issues; $\mathbf{M L}=$ the ratio of FTSE All-Share index relative to its 12-month moving average; MRun = cumulative 6-month FTSE returns; GEYR= gilt to equity yield ratio; $\Delta \mathbf{3 b i l l s}=$ the percentage change in 3-month T-bill; DCEF = the level of the average discounts on closed-end funds: $\mathbf{B C}=$ Business cycle dummy equals to one during periods of economic expansions and zero otherwise; $\mathbf{C C I}_{\mathbf{t}-4}=$ the lagged value of the ratio of consumer confidence index (CCI) to its 12-month moving average; MV= the 90-day market volatility expressed as a percentage; AAPR $(\%)=$ the cumulative average abnormal returns in the previous three months; $\mathbf{A C} \_\mathbf{M}$. = a seasonal dummy, equal to 1 and zero otherwise, for March, June, July and December; and NA_M.= a seasonal dummy, equal to 1 and zero otherwise, for January, August and September. 
Table B4. Pearson correlation coefficients for quarterly rights issues, 1975-2007

\begin{tabular}{|c|c|c|c|c|c|c|c|c|c|c|c|c|}
\hline & N_Issues & ML & MRun- & GEYR & $\Delta$ 3bills & DCEF & BC & CCIt-4 & $\operatorname{AAPR}(\%)$ & MV & Reg. & AC_Q \\
\hline N_ Issues & 1.00 & & & & & & & & & & & \\
\hline ML & 0.36 & 1.00 & & & & & & & & & & \\
\hline MRun & 0.43 & 0.35 & 1.00 & & & & & & & & & \\
\hline GEYR & 0.58 & 0.51 & 0.27 & 1.00 & & & & & & & & \\
\hline$\Delta$ 3bills & 0.05 & 0.05 & 0.02 & 0.10 & 1.00 & & & & & & & \\
\hline DCEF & 0.11 & 0.18 & 0.07 & 0.45 & 0.07 & 1.00 & & & & & & \\
\hline BC & -0.15 & 0.16 & -0.12 & -0.01 & 0.08 & -0.10 & 1.00 & & & & & \\
\hline $\mathrm{CCI}_{\mathrm{t}-4}$ & 0.11 & 0.06 & 0.13 & 0.12 & -0.20 & -0.02 & 0.08 & 1.00 & & & & \\
\hline AAPR (\%) & -0.02 & -0.40 & 0.03 & -0.02 & -0.11 & 0.30 & -0.13 & 0.07 & 1.00 & & & \\
\hline Vol. & 0.10 & 0.22 & 0.24 & 0.02 & 0.13 & -0.04 & 0.08 & 0.03 & -0.07 & 1.00 & & \\
\hline Reg. & -0.64 & -0.30 & -0.19 & -0.61 & -0.02 & -0.50 & 0.29 & -0.03 & -0.01 & 0.03 & 1.00 & \\
\hline AC_Q & 0.24 & 0.09 & 0.14 & 0.06 & 0.13 & 0.02 & 0.01 & 0.03 & -0.01 & 0.12 & 0.00 & 1.00 \\
\hline
\end{tabular}

Note. Num_Issues= number of rights issues; $\mathbf{M L}=$ the ratio of FTSE All-Share index relative to its 12-month moving average; MRun = cumulative 6-month FTSE returns; GEYR= gilt to equity yield ratio; $\Delta \mathbf{3 b i l l s ~}=$ the percentage change in 3-month T-bill; $\mathbf{D C E F}=$ the level of the average discounts on closed-end funds: $\mathbf{B C}=$ Business cycle dummy equals to one during periods of economic expansions and zero otherwise; $\mathbf{C C I}_{\mathbf{t}-4}=$ the lagged value of the ratio of consumer confidence index (CCI) to its 12-month moving average; $\mathbf{M V}=$ the 90 -day market volatility expressed as a percentage; AAPR $(\%)=$ the cumulative average abnormal returns in the previous three months; AC_Q.= a seasonal dummy equal to 1 in the second calendar quarter of each year and zero otherwise.

\section{Copyrights}

Copyright for this article is retained by the author(s), with first publication rights granted to the journal.

This is an open-access article distributed under the terms and conditions of the Creative Commons Attribution license (http://creativecommons.org/licenses/by/3.0/). 